\title{
EDUCAÇÃO SEXUAL PARA ALÉM DA SALA DE AULA: INTERVENÇÃO EDUCATIVA SOBRE HIV/AIDS PARA ESTUDANTES DO ENSINO MÉDIO
}

\author{
SEX EDUCATION BEYOND THE CLASSROOM: EDUCATIONAL \\ INTERVENTION ABOUT HIV/AIDS FOR HIGH SCHOOL STUDENTS
}

\author{
Marinete Silva Santos ${ }^{1}$ \\ Gilderlene Aires Santos ${ }^{2}$ \\ Simone Marques Almeida ${ }^{3}$ \\ Anny Karoline Rodrigues Batista ${ }^{4}$ \\ Carlos Alailson Licar Rodrigues ${ }^{5}$
}

\begin{abstract}
Resumo: Este estudo objetivou verificar o papel da escola sobre a prática de prevenção e combate ao HIV/AIDS por meio de ações/programas de educação em saúde na sala de aula, e fornecer subsídios para a realização de intervenções educativas aos estudantes do Ensino Médio. Um estudo qualitativo, transversal e descritivo foi realizado através da aplicação de questionários estruturados e ações programadas na escola. Identificou-se pouco conhecimento dos alunos sobre a temática e, nesse contexto, observou-se a necessidade de inserção da temática na sala de aula e para além dela, articulando família, escola, sociedade e governo municipal com o intuito de disseminar informações e a aplicabilidade entre elas, de modo a aproximar a comunidade à realidade epidemiológica da cidade. Por fim, ficou evidente a aceitação da sociedade, demonstrando que essas práticas podem ser estimuladoras e validadas como ferramentas de promoção da cultura dos cuidados com a saúde em sala de aula.
\end{abstract}

Palavras-chave: Educação em saúde; HIV/AIDS; Metodologias ativas; Projeto integrador.

Abstract: This study aimed to verify the school's role on the practice of preventing and combating HIV/AIDS through health education actions/programs in the classroom and providing subsidies for carrying out educational interventions for high school students. A qualitative, cross-sectional and descriptive study was carried out through the application of structured questionnaires and programmed actions at the school. Little knowledge of the students on the theme was identified and, in this context, the need to approach the theme in the classroom and beyond was observed, articulating the family, the school, society and municipal government in order to publicize information and theapplicability among them, in order to bring the community closer to the city's epidemiological reality. Therefore, society's acceptance was evident, demonstrating that these practices can be stimulating and validated as tools to promote the culture of health care in the classroom.

\footnotetext{
${ }^{1}$ Licenciada em Ciências com Habilitação em Biologia pela Universidade Estadual do Maranhão (UEMA), Programa Darcy Ribeiro, Pólo Santa Luzia, Maranhão, Brasil. E-mail: marynethsanttos@gmail.com

${ }^{2}$ Licenciada em Ciências com Habilitação em Biologia pela Universidade Estadual do Maranhão (UEMA), Programa Darcy Ribeiro, Pólo Santa Luzia, Maranhão, Brasil. E-mail: derlaaires@ gmail.com

${ }^{3}$ Licenciada em Ciências com Habilitação em Biologia pela Universidade Estadual do Maranhão (UEMA), Programa Darcy Ribeiro, Pólo Santa Luzia, Maranhão, Brasil. E-mail: symonnemarks@ gmail.com

${ }^{4}$ Mestranda em Biodiversidade, Ambiente e Saúde pela Universidade Estadual do Maranhão (UEMA), Campus Caxias. Bacharel em Enfermagem pela Universidade Estadual do Maranhão (UEMA), Campus Santa Inês, Maranhão, Brasil. E-mail: karol_rodrigues.b@hotmail.com

${ }^{5}$ Doutorando em Ciência Animal pela Universidade Estadual do Maranhão (UEMA), Campus Paulo VI, São Luís, Maranhão, Brasil. E-mail: carlos_licar@hotmail.com
} 


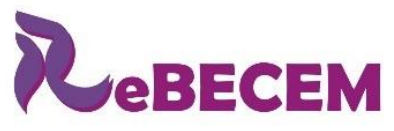

DOI: http://dx.doi.org/10.33238/ReBECEM.2020.v.4.n.1.23922

Keywords: Health education; HIV/AIDS; Active methodologies; Integrating project.

\section{Introdução}

A Síndrome da Imunodeficiência Adquirida (AIDS) é uma Infecção Sexualmente Transmissível (IST) causada pelo Vírus da Imunodeficiência Humana (HIV). O contágio do patógeno se configura por várias vias, tais como compartilhamento de objetos cortantes ou perfurantes, relação sexual desprotegida, transmissão vertical (da mãe para o feto no útero ou do recém-nascido durante o parto) e/ou pelo aleitamento materno. $\mathrm{O}$ vírus, em alguns casos, apresenta um longo período de incubação, o qual se estende por meses ou anos para manifestar os primeiros sintomas, e os indivíduos acometidos terão o sistema imunológico debilitado, ficando vulneráveis às doenças oportunistas, desde viroses à diversos tipos de câncer, o que pode tornar o tratamento mais difícil (MINISTÉRIO DA SAÚDE, 2014).

De acordo com o Núcleo de Estudos para a Prevenção da AIDS (NEPAIDS), os primeiros casos foram reconhecidos durante a década de 1980, sendo documentados em uma população homoafetiva masculina que manifestava um conjunto de sintomas (Sarcoma de Kaposi, Pneumonia e a imunidade debilitada) provenientes de cidades norteamericanas como Nova York, Los Angeles e São Franscisco. Em virtude disso, a doença esteve inicialmente relacionada à uma deficiência imunológica associada aos gays. Estudos epidemiológicos publicados também durante a década de 1980 apontam para os primeiros registros na África e Haiti, e, posteriormente, na Dinamarca e Reino Unido (1981). Nos Estados Unidos da América (EUA), o primeiro registro de caso de AIDS se deu em uma pessoa hemofílica por meio de transfusão sanguínea, e a grande incidência da doença ocorreu em populações de grandes cidades, como São Francisco e Nova York (GRMEK, 1995).

Nesse âmbito, por ter sido detectada inicialmente na comunidade homoafetiva, a AIDS ficou conhecida como a "peste gay" ou doença dos 5H (homossexuais, hemofílicos, haitianos, heroinômanos e hookers), nomes atribuídos antes da identificação e classificação do vírus e da doença (EBERTZ, 2017). Atualmente esse termo é inutilizado, pois a disseminação da infecção está mais direcionada aos hábitos e estilos de vida dos indivíduos do que a um grupo específico.

No Brasil, os primeiros relatos de casos de AIDS foram documentados em meados de julho de 1982, em São Paulo. Porém estudos retrospectivos demonstraram casos 
DOI: http://dx.doi.org/10.33238/ReBECEM.2020.v.4.n.1.23922

registrados em 1980, ano que notadamente ficou conhecido como o marco inicial do surgimento da AIDS no País (MARQUES, 2002).

Dito isso, importa lembrar que em anos posteriores os registros de novas infecções pelo HIV no Brasil obtiveram uma redução de $16 \%$ desde 2010, sendo 2,1 milhões nesse ano em comparação com 1,7 milhões em 2018. Mesmo com a diminuição de casos, o Brasil ainda apresenta aumento de 21\% (2010-2018) no número de pessoas infectadas quando comparado a outros países, como El Salvador (-48\%), Nicarágua (-29\%), Colômbia (-22\%) e Equador (-12\%) (UNAIDS, 2019).

Como forma de diminuir essa estatística, o Brasil tem mobilizado diversos setores da sociedade, como organizações não governamentais (ONGs), a mídia e outros grupos organizados, no sentido de formular políticas públicas direcionadas à AIDS, a exemplo do Serviço de Assistência Especializada em HIV/AIDS (SAE), do Ministério da Saúde, que estabelece cuidados assistenciais ao portador do vírus a partir de uma equipe multiprofissional, com atendimento médico especializado, psicológos, e assistência farmacêutica e psicossocial aos pacientes e familiares. Com isso, inúmeros esforços têm sido realizados buscando obter melhorias na assistência em saúde, na qualidade de vida dos portadores e com incentivos governamentais que possam garantir efetivamente as políticas públicas no País (VILLARINHO, 2013). Nesse sentido, concordamos que a escola assume uma função importante na promoção do conhecimento a partir de estratégias didáticas e projetos integradores que podem ser articulados com a comunidade escolar.

Por essa lógica, a inclusão de projetos de educação sexual nas escolas contribui para que crianças, jovens e adultos possuam uma vida saudável e tornem-se cidadãos capazes de conhecer o próprio corpo, permitindo vida social integrada à sociedade, com consciência e sensibilidade sobre aspectos preventivos e cuidados inerentes ao corpo ao longo da vida. A educação sexual abre oportunidades para que ações didáticometodológicas sejam efetivadas e contribuam para que os alunos desconstruam discursos padronizados, essencialistas e fundamentalistas que interferem no entendimento sobre a sexualidade e o gênero no âmbito das escolas brasileiras (SOUZA; MEYER; SANTOS, 2019).

Nesse contexto, inserir a escola como objeto estimulador da prática educativa sobre saúde é necessária, uma vez que promoverá a troca de experiências e facilitará o convívio social. Logo, ações em educação e saúde com o público escolar são relevantes, pois proporcionam mudanças de atitudes e possibilitam novas formas de compreensão 


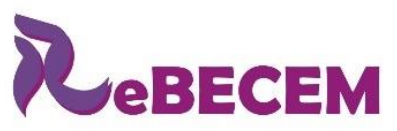

Revista Brasileira de Educação em

Ciências e Educação Matemática

DOI: http://dx.doi.org/10.33238/ReBECEM.2020.v.4.n.1.23922

dos fenômenos, sobretudo quanto às questões de respeito e cidadania. É interessante pensar a escola como um espaço de crítica, solidariedade e tolerância. Ela é corresponsável pelo desempenho de práticas ativas de prevenção ao HIV/AIDS, principalmente ao público jovem inserido em um contexto social contemporâneo e informativo.

O conhecimento tornou-se mais próximo dos jovens em virtude do desenvolvimento tecnológico e do avanço dos meios de comunicação. Esses instrumentos ocupam espaço importante na sociedade, servindo como ferramentas essenciais para a população a partir de uma lógica informacional. Segundo Angelim et al., (2015), os adolescentes são constantemente expostos à diversas formas de contágio pelo vírus, e apenas a informação teórica não garante a adoção de um comportamento preventivo. É preciso que o público seja sensibilizado sobre as práticas de prevenção do HIV, e que a escola assuma posição fundamental no sentido de promover a cultura do cuidado em seus espaços, principalmente àqueles que possuem vida sexual ativa, pois é a partir da informação e da intervenção que há a construção coletiva dos cuidados inerentes à saúde e aos comportamentos desses sujeitos (RACHID; SCHECHTER, 2017).

Numa perspectiva educacional, os Parâmetros Curriculares Nacionais (PCNs), ao proporem eixos transversais como orientação sexual, saúde e meio ambiente, possibilitam conexões com os conteúdos inerentes à disciplina de ciências, estimulando o conhecimento e a melhoria da qualidade de vida dos educandos, inserindo-os em um contexto social e cultural a partir da inserção dos conteúdos teóricos de forma transversal no currículo escolar, podendo ser priorizados conforme a realidade local e regional (MEC, 1997; COSTA, 2017; FRANCO, 2019). Essa realidade local permite que a práxis pedagógica em sala de aula seja dinâmica e flexível, podendo ser adaptada ao público assistido.

Conforme apontam Andrade, Massabni e Duarte (2011), fatores como: infraestrutura inadequada; indisponibilidade de material ou local; desconhecimento das funções investigativas das atividades curriculares; e ausência de preparo teórico/prático dos professores para lidar com as atividades, contribuem para a ineficiência de práticas educacionais por meio de ações e/ou programas de intervenção. Diante disso, é necessária a articulação da comunidade escolar de modo a promover a formação e o conhecimento entre escola e comunidade. Isso se dá através de atividades de orientação sobre o HIV/AIDS que promovam a troca de experiências entre o público escolar. A partir disso, será possível disseminar informações sobre educação em saúde na escola. 


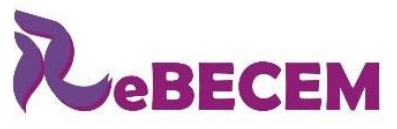

Revista Brasileira de Educação em

Ciências e Educação Matemática

DOI: http://dx.doi.org/10.33238/ReBECEM.2020.v.4.n.1.23922

Entendemos, portanto, que este estudo concretizou ações em educação em saúde na escola que permitiram uma reflexão sobre os problemas encontrados acerca da temática no município. Portanto, o trabalho objetivou verificar o papel da escola sobre a prática de prevenção e combate ao HIV/AIDS por meio de ações/programas de educação em saúde na sala de aula, fornecendo subsídios para a realização de intervenções educativas aos estudantes do Ensino Médio, no município de Santa Luzia - MA.

\section{Métodos de pesquisa}

\subsection{Caracterização do ambiente de intervenção e público-alvo}

O estudo caracterizou-se como sendo uma proposta de intervenção de cunho transversal, qualitativo e descritivo. A pesquisa qualitativa, segundo Minayo (2010), aborda questões bem específicas e pormenorizadas, havendo a preocupação em se estudar dados não quantificáveis e que não podem ser mensurados. Nesse tipo de estudo, aspectos como valores, crenças, atitudes, motivos e outras características inerentes à subjetividade, fenômenos sociais e/ou processos, são livres de quantificação por variáveis numéricas.

As atividades foram desenvolvidas por discentes de um curso de licenciatura com habilitação em Biologia do Programa de Formação de Professores Darcy Ribeiro (PDR) da Universidade Estadual do Maranhão (UEMA), no ano de 2016.

A pesquisa teve como cenário o Centro de Ensino Cícero Ferreira Silva, escola pública do município de Santa Luzia - MA. A instituição atende a jovens dos $1^{\circ}, 2^{\circ}$ e $3^{\circ}$ anos do Ensino Médio da rede pública de ensino nos turnos matutino, vespertino e noturno. A seleção da escola obedeceu ao método não-probabilístico por conveniência, considerando a necessidade de se trabalhar a educação sexual por meio de um projeto de intervenção, tendo em vista que a escola possui um público jovem com carência de informações e de conhecimentos sobre a temática.

Inicialmente, houve reuniões com professores e alunos para o diagnóstico inicial e planejamento da metodologia a ser utilizada durante a investigação. Posteriormente, aplicou-se questionários estruturados, contendo variáveis quantitativas e qualitativas de fácil pontuação, com perguntas abertas e/ou fechadas que garantiram a uniformidade, compreensão e confidencialidade nas respostas dos sujeitos. As questões levantadas nos questionários foram: (1) Você já teve alguma aula ou palestra na escola sobre HIV/AIDS? (2) Você sabe como o vírus da AIDS é transmitido? (3) Quais métodos contraceptivos você considera seguro durante as relações sexuais? (4) Quais as maneiras pelas quais 


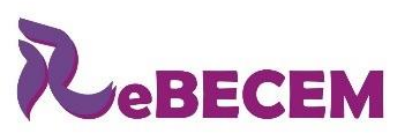

Revista Brasileira de Educação em

Ciências e Educação Matemática

DOI: http://dx.doi.org/10.33238/ReBECEM.2020.v.4.n.1.23922

uma pessoa pode ser infectada pelo vírus HIV? (5) Qual a sua opnião sobre as estratégias a serem adotadas para evitar o contágio pelo vírus HIV? (6) Qual (is) fonte (s) de informação (ões) sobre HIV/AIDS você considera importante (s) para a construção de seu conhecimento atual sobre a doença? (7) Como você avalia o estado de seu conhecimento sobre HIV/AIDS? Participaram da investigação 70 alunos matriculados nos $1^{\circ}, 2^{\circ}$ e $3^{\circ}$ anos do Ensino Médio do turno vespertino, com faixa etária dos 15 aos 17 anos, além de dez professores de diferentes componentes curriculares.

A faixa etária de 15 aos 17 anos compreende a adolescência, uma fase na qual os indivíduos apresentam uma complexa rede de transformação até a fase adulta. Essa etapa reúne um conjunto de fenômenos biológicos, tais como maturação hormonal e crescimento somático que contribuem para o processo de reprodução e desenvolvimento corporal (COUTINHO, 2011). Isso permite que a temática seja discutida constantemente entre os adolescentes, sobretudo no espaço escolar, uma vez que auxiliam na orientação e sensibilização deles acerca da educação sexual.

\subsection{Aspectos éticos da pesquisa}

As atividades foram realizadas obedecendo a todos os padrões éticos em pesquisas realizadas com os seres humanos, conforme Resolução n ${ }^{\circ}$ 510/2016 do Conselho Nacional de Saúde (CNS). Utilizou-se o Termo de Consentimento Livre e Esclarecido (TCLE) junto aos alunos, conforme Resolução 196/1996 e modelos disponibilizados pelo Comitê de Ética em Pesquisa da Universidade Estadual do Maranhão (CEP/UEMA), que documentam a autorização dos estudantes. Esses foram informados sobre os procedimentos adotados, riscos, desconfortos, benefícios e direitos envolvidos.

\subsection{Programa de intervenção da comunidade escolar}

As ações de educação em saúde foram articuladas em três momentos:

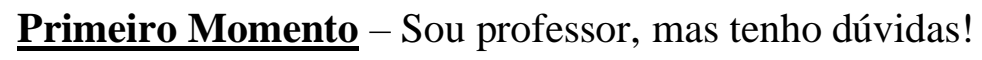

Por meio da aplicação de questionários, realizou-se um trabalho com professores e alunos com diálogos abertos sobre educação sexual; frequência de diálogos com os pais sobre sexualidade; práticas e comportamentos sexuais; curiosidades sobre educação sexual e etnoconhecimento sobre HIV/AIDS. As dúvidas dos professores foram esclarecidas, tais como: como se trabalhar a temática educação sexual na sala de aula? quais assuntos podem estar associados aos temas transversais orientação sexual, saúde e 


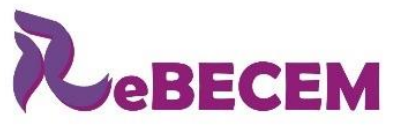

Revista Brasileira de Educação em

Ciências e Educação Matemática

DOI: http://dx.doi.org/10.33238/ReBECEM.2020.v.4.n.1.23922

meio ambiente? quais as metodologias disponíveis para abordar tal temática? Essas questões foram evidenciadas posteriormente no planejamento das ações. Em seguida, cópias do projeto foram entregues aos professores como documento norteador das práticas pedagógicas em atividades futuras, disponibilizando a eles oportunidades de desenvolverem atividades didático-metodológicas capazes de promover o diálogo, a participação e o debate entre os alunos, além da articulação dos conteúdos curriculares aos temas transversais disponíveis a partir dos PCNs (educação sexual, saúde e meio ambiente).

O projeto norteador da práxis pedagógica foi construído a partir do diagnóstico inicial, considerando as contribuições dos professores, como: inserir no Projeto Político Pedagógico (PPP) atividades como debates, seminários, dinâmicas sobre educação sexual; e envolver os pais dos alunos nas atividades escolares e estimulá-los a discutirem a temática no âmbito familiar. Nesse momento, a parceria entre universidade, escola e comunidade foi necessária para o alcance dos objetivos propostos, em que se solidificaram, a partir dos diálogos permanentes, da importância da universidade como instituição formadora de recursos humanos e como espaço de construção e socialização do saber. Nessa perspectiva, assumiu-se o papel da escola como instituição co-formadora, uma vez que acolheu o projeto pedagógico em seus espaços.

Posterior às ações descritas anteriormente, um grupo de líderes de sala foi criada, que passou a integrar a equipe do projeto, cujo intuito foi o de contribuir com sugestões, opiniões e ideias para o desenvolvimento da proposta. Baseando-se nisso, foi possível elaborar previamente ações em sala de aula, inicialmente denominadas de "DIA + (Diálogo + Informação = Adesão $)$ ".

Quanto às atividades, sugeriu-se aos alunos que colocassem em uma caixa perguntas sobre algo que eles tinham curiosidade acerca dos temas como IST, sistema reprodutor, métodos contraceptivos, preconceito etc. Durante essa atividade, realizada de forma espontânea, esperou-se que os participantes elaborassem perguntas sobre os temas, mas sem se identificarem no papel. Essa estratégia foi importante para resguardar a confidencialidade dos sujeitos. O objetivo dessa estratégia foi promover o diálogo e instigar o conhecimento dos alunos, bem como a participação deles. Nessa fase, não foi obrigatória a exposição das respostas perante a turma, visto que se tratou de temas que permeiam a intimidade da maioria dos envolvidos.

Ao final da ação anterior, sugestões, ideias e opiniões foram compiladas a fim de propor diálogos e incorporá-los ao planejamento do projeto, promovendo, dessa forma, a 


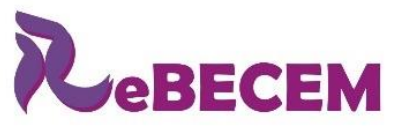

DOI: http://dx.doi.org/10.33238/ReBECEM.2020.v.4.n.1.23922
Revista Brasileira de Educação em

Ciências e Educação Matemática

participação ativa dos envolvidos. Entre as contribuições recebidas dos alunos, pode-se destacar:

- É preciso ter estímulo dos professores em abordar com frequência os temas sobre educação sexual na escola;

- Realização de aulas práticas com a construção e uso de modelos didáticos que auxiliem no ensino de ciências e;

- Realização de palestras informativas de modo frequente na escola, bem como promoção de diálogos entre os sujeitos envolvidos no processo (alunos, professores e gestor) acerca da temática abordada.

A partir dessas respostas, foi possível planejar com mais segurança e detalhe as etapas seguintes.

$\underline{\text { Segundo Momento }}$ - Trocando ideias

Munidos do material produzido na etapa anterior e com os dados sobre casos de HIV/AIDS do município e o conhecimento das necessidades dos alunos, os professores promoveram discussões sobre educação sexual junto aos alunos, atividade que se estendeu durante duas semanas. Essa ação assistiu um total de 245 alunos, em que cada docente buscou trabalhar a temática de forma transversal e interdisciplinar, despertando e envolvendo os alunos nas atividades em sala de aula, e respeitando a fidelidade dos conteúdos abordados. Diante da aceitação dos estudantes, atividades, discussões e diálogos sobre HIV/AIDS, ISTs, métodos contraceptivos, tabus e preconceitos, sistema reprodutor masculino e feminino foram abordados por uma equipe composta de sete professores, em diferentes turmas.

Terceiro Momento - Vamos compartilhar. Calar não resolve!

Partindo do princípio de que só há adesão a uma informação se existir diálogo, foi lançado o DIA +, planejado inicialmente no primeiro momento, e que norteou os debates sobre educação sexual, abrangendo assuntos que, em sua maioria, são vistos como tabus pela sociedade. Nesse sentido, o envolvimento da comunidade escolar foi imprescindível para que o conhecimento fosse veiculado e acolhido de forma eficaz pelo público. A escola reservou um dia para a realização dessa atividade. Para isso, foram montados espaços nas salas de aula que foram denominados "galerias de informação". Estes espaços proporcionaram diálogos e contato dos alunos com temas correlatos, tais como: formas de transmissão do vírus HIV; medidas de prevenção; tratamento; assistência médica; entre outros. Cada tema foi planejado para um tempo estimado de 45 minutos, ministrado, 
DOI: http://dx.doi.org/10.33238/ReBECEM.2020.v.4.n.1.23922

simultaneamente, por palestrantes especialistas, de forma dinâmica, com o uso de recursos didáticos, como o projetor data show.

Para participação nas palestras, a equipe organizou inscrições dos alunos nas galerias de informação. Cada aluno poderia se inscrever em duas galerias. Após as inscrições, os alunos direcionavam-se às galerias para informação e interação entre os pares. Ao final do DIA +, todos os participantes receberam certificados. Os pais dos alunos foram contatados por meio de carta-convite, a partir da qual houve a sugestão de comparecimento no dia das ações. O roteiro apresentado foi o seguinte: apresentação da pesquisa; assinatura do TCLE; e esclarecimentos e exposição das atividades planejadas, de modo a promover participação e diálogo entre os participantes. Nessa fase, os pais demonstraram forte aceitação e reafirmaram a importância de uma abordagem dessa natureza no âmbito escolar, uma vez que permite que seus filhos se tornem membros participativos e informados sobre temas de amplitude social e cultural. Esses argumentos fortaleceram a necessidade da informação e orientação no âmbito familiar.

Organizou-se um debate com pais e alunos, tendo o seguinte tema: Discussão do tema "Orientação Sexual” no ambiente familiar. Para acolhimento dos pais, procurouse construir um espaço agradável de modo a propiciar um momento para a troca de informação e promoção do diálogo. O debate foi organizado considerando-se opiniões expressas: pais que discutiam orientação sexual com os filhos e pais que não discutiam educação sexual com os filhos. Em seguinda, destacou-se as opiniões dos envolvidos. Durante toda a intervenção, a equipe da proposta procurou esclarecer a importância do discurso na família, deixando claro que a informação é o passo inicial para a promoção da cultura dos cuidados inerentes à saúde e à educação. De forma a complementar as ações, buscou-se construir caixas contendo frases como: "tenho dúvida" e "mito ou verdade?", que foram inseridas no pátio da escola para que os alunos participassem e tivessem a liberdade de esclarecer dúvidas sobre assuntos relacionados à temática, valendo-se do anonimato. Os questionamentos levantados pelos alunos foram respondidos dentro da galeria "tire sua dúvida".

Ao final das ações, realizou-se uma blitz urbana de cunho informativo durante o turno vespertino, em uma importante avenida da cidade de Santa Luzia (MA), com a participação de todos os alunos, professores e a gestora escolar. Essa intervenção foi marcada por informações e a participação coletiva com o uso de uma faixa (contendo a frase "HIV/AIDS - Previna-se") e balões informativos (contendo informações sobre o número de casos reportados para o município, estímulo à prevenção, e a seguinte frase: 


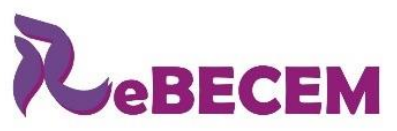

Revista Brasileira de Educação em

Ciências e Educação Matemática

DOI: http://dx.doi.org/10.33238/ReBECEM.2020.v.4.n.1.23922

"HIV/AIDS - Previna-se"). Além disso, houve apitos para controle das pessoas e também outros cartazes contendo informações sobre a temática, que foram elaborados pelos próprios alunos. Essa ação foi apoiada por um carro de som, de forma a atingir um grande público, com o intuito de disseminar o conhecimento à comunidade, sensibilizá-la e estreitar as relações com a escola. Panfletos foram produzidos e distribuídos pela equipe de líderes da escola durante toda a ação; esses panfletos continham informações sobre conceitos de HIV/AIDS e formas de contaminação e prevenção do vírus HIV. Durante a ação, os participantes usaram laço vermelho, símbolo da luta contra o HIV/AIDS em campanhas de saúde.

\subsection{Campanhas educativas na escola}

A promoção de campanhas educativas na escola é essencial, pois, a partir delas, os alunos se tornarão sujeitos multiplicadores do conhecimento. Nesse contexto, buscouse planejar ações concretas que envolveram a Secretaria Municipal de Saúde, articulandoa à escola. Utilizou-se materiais fornecidos pela secretaria, como panfletos, folders, cartazes, preservativos etc. A equipe executora elaborou folders informativos e ilustrativos que trataram da temática HIV/AIDS. De forma adicional, elaborou-se os seguintes materiais: questionários que constituíram suas aplicabilidades junto aos docentes e discentes contendo perguntas relacionadas à temática, cujo objetivo foi o de esclarecer dúvidas dos alunos, além da elaboração de uma cartilha educativa como produto para a orientação e sensibilização dos pais. Ao final, uma palestra foi proferida por um profissional de saúde do município, cujo tema foi " $\mathrm{O}$ contexto histórico, epidemiológico e social do HIV-AIDS".

\subsection{Análise estatística}

A análise estatística e tabulação dos dados foram organizados por meio de cálculos de porcentagens, de acordo com as categorias de respostas dos entrevistados. Para isso, utilizou-se o Microsoft Excel 2010, que permitiu a geração dos dados numéricos e gráficos. A análise das respostas dos entrevistados foi feita com base em informações aprofundadas e ilustrativas de forma a permitir uma melhor compreensão da dinâmica desse processo.

\section{Resultados e Discussões}


DOI: http://dx.doi.org/10.33238/ReBECEM.2020.v.4.n.1.23922

As discussões acerca do HIV/AIDS são indispensáveis, tanto na sala de aula quanto em outros espaços informais. $\mathrm{O}$ advento da tecnologia contribui para a elucidação do conhecimento sobre as novas formas de prevenção. Entretanto, nem todas as fontes são confiáveis e seguras, pois ainda existe muita informação conflitante por serem desatualizadas e não contextuais, o que contribui para a insegurança e o preconceito social existente.

Trabalhos que visam o esclarecimento de dúvidas, contradições e mitos devem ser vistos como instrumentos de informação que contribuem para o conhecimento da população. Apesar dos inúmeros avanços, nenhum se compara ao combate a tabus sexuais. Muitos adolescentes e/ou jovens confundem os conceitos de HIV e AIDS, apresentando deficiência no entendimento. Por isso, torna-se importante dar atenção especial à promoção do diálogo e a trabalhos pedagógicos que contribuam para a diminuição dos elevados índices de contaminação pelo vírus.

Os alunos foram questionados acerca do grau de conhecimento que tinham sobre as formas de prevenção, tratamento e controle do vírus HIV/AIDS, tendo a oportunidade de categorizá-las em: 1 - não conhece; 2- muito pouco; 3 - pouco; 4 - bem; 5 - muito bem. Utilizou-se a Escala de Likert com intervalo de 1 - 5, sendo 1 (não conhece o assunto) e 5 (conhece muito bem o assunto). Esta escala é capaz de mensurar as atitudes e os comportamentos dos entrevistados (LIKERT, 1932).

Os resultados demonstraram que 37\% (29 alunos) conhecem as formas de prevenção, tratamento e controle do HIV/AIDS, porém, a maioria deles $(39,7 \%)$ ainda compreende pouco o assunto (Fig. 1). De acordo com Carpilovsky et al., (2010), embora haja consenso entre os estudiosos em promover discussões sobre educação sexual nas escolas, na prática, os educadores e os pais ainda apresentaram resistências a dialogar com os jovens. Segundo os autores, temas transversais, como educação sexual e saúde, não são discutidos como deveriam. A partir deles os professores teriam a possibilidade de agregar temas geradores, promover a discussão em seus espaços educativos e incentivar a interdisciplinaridade. 
DOI: http://dx.doi.org/10.33238/ReBECEM.2020.v.4.n.1.23922

Figura 1: Nível de conhecimento prévio dos alunos sobre o vírus HIV/AIDS

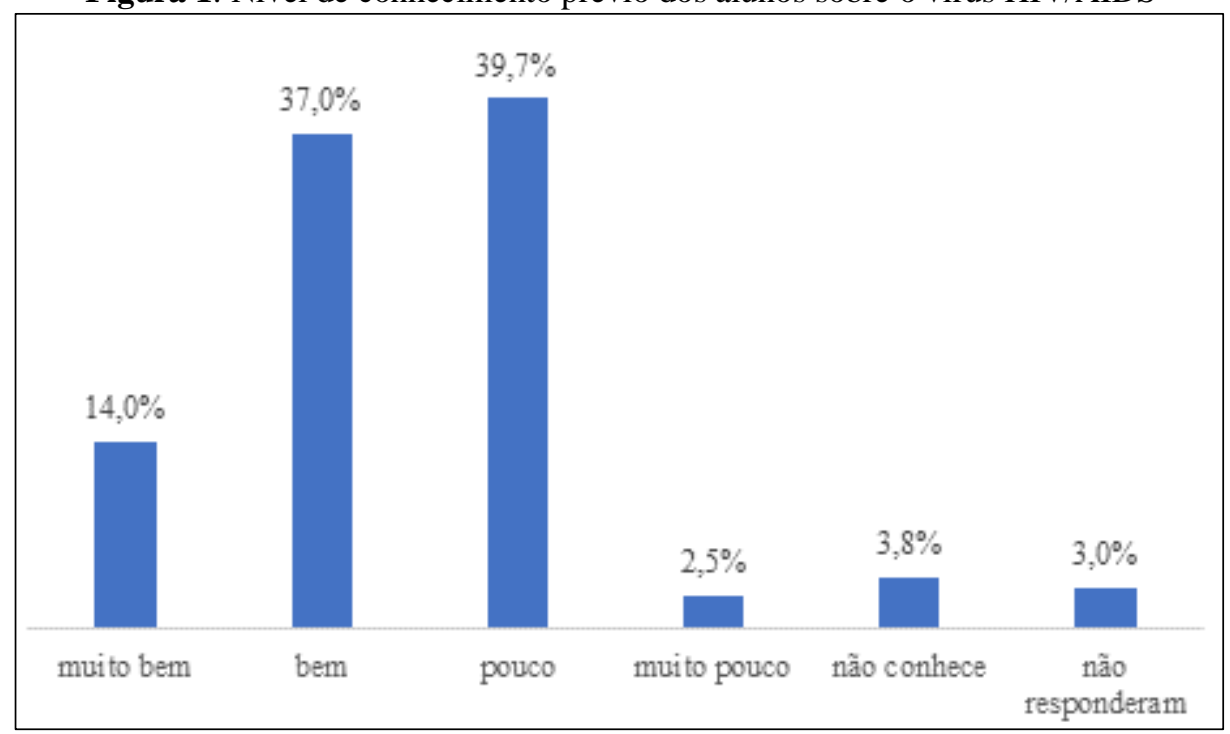

Fonte: Elaborado pelos autores (2019)

Os alunos, quando questionados sobre quais métodos consideram seguros, apontaram o uso do método de barreira (preservativo masculino) - trata-se do mais conhecido, relatando que é uma forma eficiente de evitar a contaminação pelo vírus. Os alunos reconheceram a importância da utilização de métodos seguros durante as relações sexuais, principalmente para evitar a gravidez indesejada, entre os quais destacaram o preservativo feminino, DIU e pílula anticoncepcional. Esses dados vêm ao encontro dos relatados por Gomes et al., (2019), em que alunos de uma escola pública os citaram como métodos contraceptivos importantes para a prevenção de ISTs, sobretudo a gravidez. Sabe-se que, por várias razões, os jovens formam um grupo com elevada vulnerabilidade frente ao HIV, seja por seus hábitos ou atitudes devido à faixa etária. Assim, esse conhecimento contribui para que os educandos estabeleçam a cultura dos cuidados com a saúde (RODRIGUES et al., 2016).

Para Cunha (2015), estudos realizados com esse público revelam a resistência e o preconceito acerca do uso do preservativo; cita-se desconforto e falta de hábitos, o que contribui significativamente para disseminação, não somente do HIV, mas de outras ISTs. Outrossim, para Dourado et al., (2015), promover uma cultura consistente no uso do preservativo é um desafio que requer intervenções práticas e contínuas junto à comunidade, principalmente no ambiente escolar. 


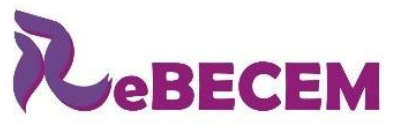

\section{Revista Brasileira de Educação em \\ Ciências e Educação Matemática}

DOI: http://dx.doi.org/10.33238/ReBECEM.2020.v.4.n.1.23922

As diversas formas pelas quais um indivíduo pode ser infectado pelo vírus HIV foram descritas pelos alunos segundo suas crenças, e, entre elas, destaca-se: compartilhamento de objetos pessoais (seringas, alicates de unhas, tesouras etc.); relações sexuais; transfusão sanguínea; atitudes como abraçar, beijar; uso de banheiros; aperto de mãos; e o mais curioso: transmissão por picadas de insetos. Nesses relatos, percebe-se o baixo conhecimento dos alunos frente à temática (Fig. 2).

Figura 2: Conhecimento dos alunos sobre o que eles consideram como método seguro para a transmissão do HIV

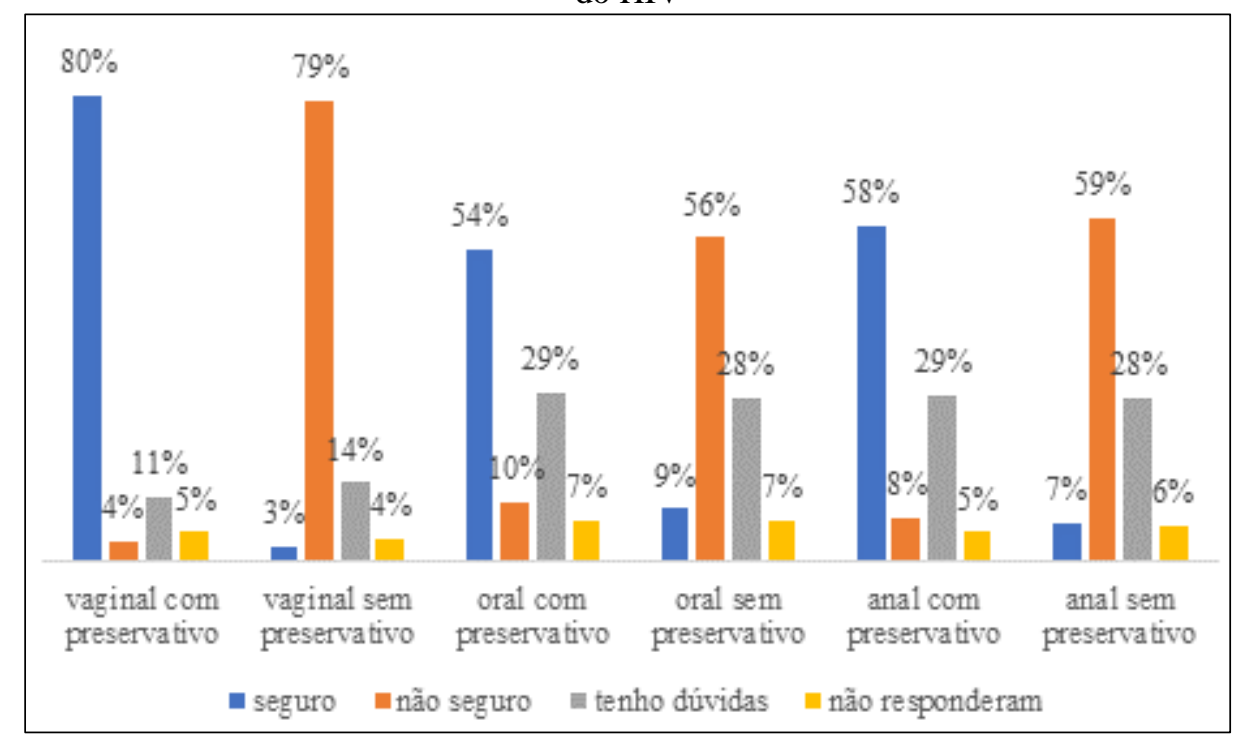

Fonte: Elaborado pelos autores (2019)

Acerca dos conhecimentos prévios dos discentes sobre as formas de transmissão do vírus HIV, mesmo diante do número expressivo dos que afirmam conhecer, ainda se percebe a falta de informação por parte de alguns alunos. Isso deixa claro que a discussão desses temas na escola permite que eles se tornem sujeitos informados sobre questões que afetam sua saúde e qualidade de vida (Fig. 3).

Figura 3: Conhecimento dos alunos quanto aos modos de transmissão do vírus HIV 
DOI: http://dx.doi.org/10.33238/ReBECEM.2020.v.4.n.1.23922

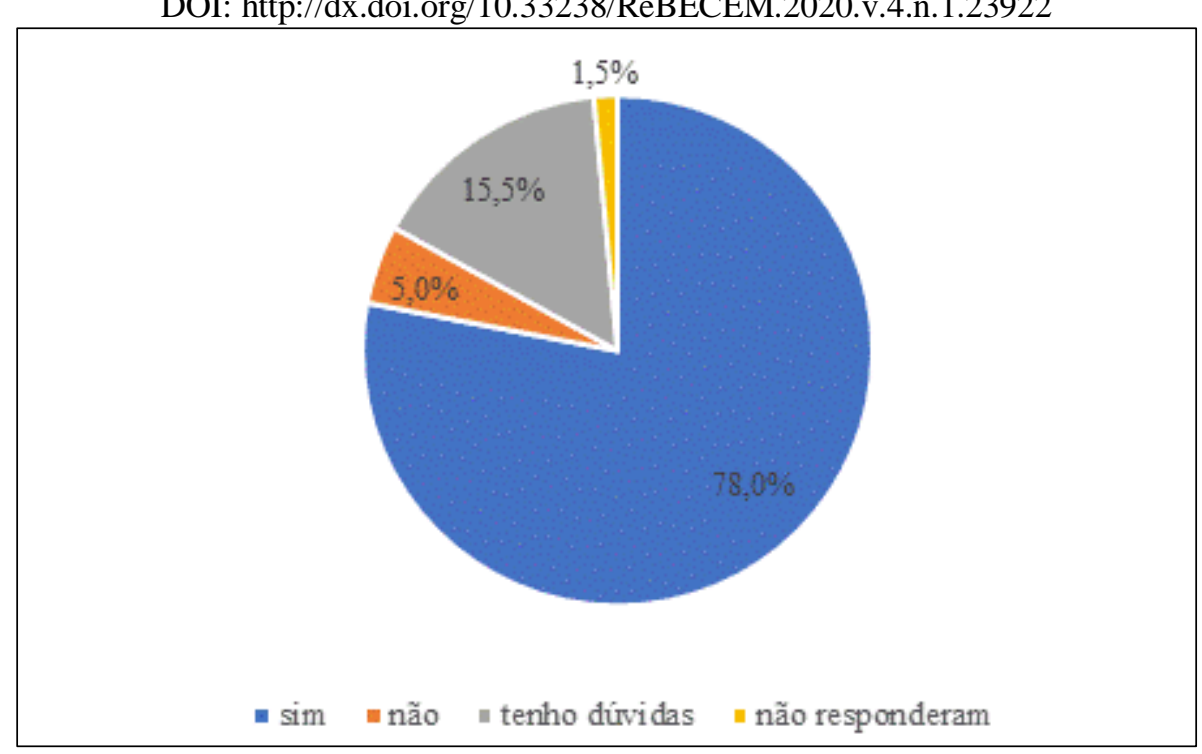

Fonte: Elaborado pelos autores (2019)

Costa (2017) vem afirmar que a escola é um espaço de socialização do conhecimento, e que dialogar sobre AIDS é um desafio, devendo promover o envolvimento de todos. A escola, como espaço social, precisa divulgar informações, promovendo debates democráticos e propondo discussões entre os alunos, informandoos sobre práticas, comportamentos e atitudes que reduzem os riscos de infecções, oferecendo opções e condições para que as informações possam ser interiorizadas e melhor compreendidas.

Entre os assuntos discutidos pelos alunos, 90\% (63 alunos) deles reconhece a importância do diálogo entre colegas e amigos, bem como o uso do preservativo durante a relação sexual. A sociedade possui papel importante na formação e desenvolvimento dos sujeitos no que diz respeito às atitudes, competências e habilidades (FONSECA et al., 2010). Nesse sentido, os autores reforçam a ideia de que o adolescente/jovem desempenha um papel fundamental como agente multiplicador do conhecimento, dos valores e concepções, sendo, portanto, sujeito participativo no processo educativo.

Ao questionarmos sobre os dados apontados pelos alunos sobre a frequência dos diálogos acerca do tema IST/HIV/AIDS, 53,8\% (42 alunos) afirmou que discutia o tema com os amigos; 43,5\% (44 alunos) com professores; e 42,3\% (33 alunos) com seus pais. Fica explícito que o diálogo é a base para o esclarecimento de dúvidas nos espaços sociais, questões estas que se relacionam com a saúde sexual e fatores biológicos intrínsecos ao ser humano. Sousa (2015) menciona que educar significa formar pessoas, criando condições para que as crianças cresçam conscientes e responsáveis por seus atos. É compreensível que o conhecimento parta do princípio do diálogo, ou seja, deve advir de 


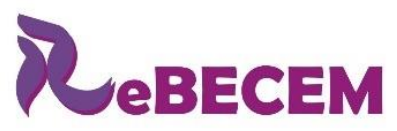

Revista Brasileira de Educação em

Ciências e Educação Matemática

DOI: http://dx.doi.org/10.33238/ReBECEM.2020.v.4.n.1.23922

conversas constantes e esclarecedoras no âmbito familiar, e que transmita confiança entre professor/família/aluno, pois, tanto os docentes quanto os pais tornam-se sujeitos centrais do processo informativo.

Este tema, em inúmeras situações, é evitado pelos jovens e visto como barreira, pois o consideram “desconfortável” (FONSECA et al., 2010). Alguns pais sentiam dificuldade em discutí-los; isso foi claro em uma das falas: P1- "Tenho dificuldade de conversar com meus filhos sobre educação sexual. Não tenho o conhecimento suficiente para abordar isso em casa". Nesse relato, percebeu-se que os pais precisam da informação e da proximidade familiar, de modo que possibilite um diálogo aberto e harmônico com os filhos. P2- "Moro na zona rural e não tenho acesso às informações sobre esse assunto. Aqui temos muita dificuldade em entender essas coisas por conta disso”. Nessa fala, verificou-se a falta de acesso aos meios de comunicação. Esses, como se sabe, contribuem fortemente para a aquisição do conhecimento e, consequentemente, para a informação dos filhos sobre questões que envolvem o corpo e atitudes sexuais. Muitos pais relataram haver constrangimento, e que um diálogo seguro e aberto influenciaria seus filhos em seus comportamentos sexuais.

Os Parâmetros Curriculares Nacionais (PCNs) (1997, p. 304) destacam que "O trabalho de orientação sexual compreende a ação da escola como complementar à educação dada pela família”. Nesse sentido, pode-se inferir que a família é corresponsável pela socialização, exercendo influência na saúde de seus membros.

Os alunos foram questionados sobre a possibilidade de obtenção de aulas e/ou palestras acerca do HIV/AIDS na escola, e no universo de 70 alunos, 52,5\% (41 alunos) já obteve algum contato com o tema.

Ao mencionarem seus pontos de vista sobre quais fontes de informação buscavam referente ao HIV/AIDS, 66,6\% (52 alunos) relataram, por inúmeros motivos, que o (a) professor (a) é um peça fundamental na disseminação das informações, já que os alunos possuem segurança em seu conhecimento e nas relações que estabelecem com eles (elas) em sala de aula (Fig. 4). Muitos desses alunos encontram nos docentes a confiança e segurança para o diálogo. Para Fonseca, Gomes e Teixeira (2010), torna-se fundamental a busca por novas tecnologias, ou seja, é necessário almejar novas formas de agir, argumentar e ousar, pois, assim, será possível aos adolescentes se tornarem cidadãos capazes de viver de forma saudável, aproveitando seus prazeres de forma consciente e responsável. Nesse sentido, focamos na importância do educador para a formação escolar e social de jovens e adolescentes, buscando uma melhor qualidade de vida e de saúde. 


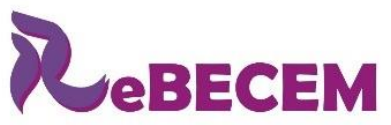

DOI: http://dx.doi.org/10.33238/ReBECEM.2020.v.4.n.1.23922

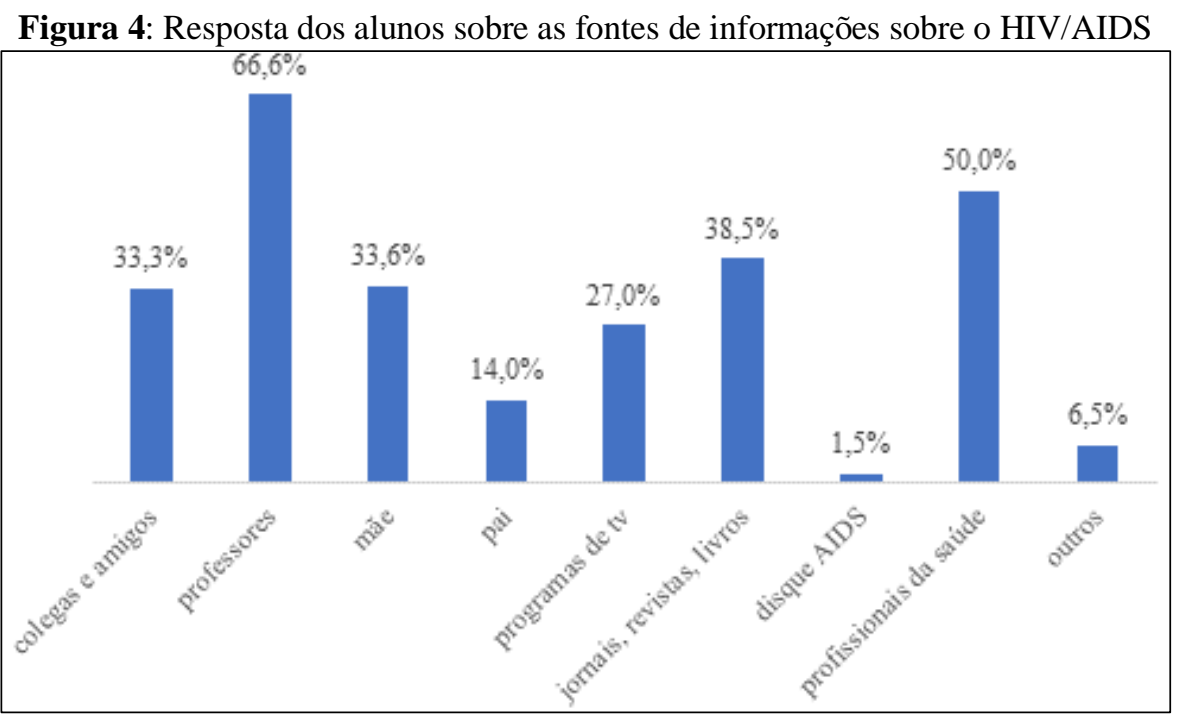

Fonte: Elaborado pelos autores (2019)

Fica evidente, com base nos dados apresentados, que há necessidade de mediação de informações direcionadas aos alunos por parte dos professores. A adolescência é uma fase de descobertas e amadurecimento corporal e pessoal, em que os indivíduos passarão, até chegar à vida adulta, por vários conflitos relacionados à sexualidade, biologia e relações pessoais, estando sujeitos às influências sociais e culturais (CODEPPS, 2006). Nesse contexto, os adolescentes precisam de esclarecimentos, devendo ser sustentados tanto no âmbito escolar quanto familiar.

Diante das discussões realizadas com os educadores durante as intervenções nas entrevistas e rodas de conversa, os professores e professoras deixaram clara a importância do diálogo em sala de aula, bem como fora dela, em virtude da repercussão epidemiológica do HIV/AIDS, principalmente no município de Santa Luzia, e relataram que, na maioria das vezes, a escola não aborda a temática.

Os docentes perceberam a importância dos procedimentos e das ações a partir de projetos integradores que envolvam a comunidade e a escola através de metodologias ativas que propiciam avanços sociais significativos na luta contra os tabus existentes sobre a doença. Essas questões denotam a importância das atividades que envolvem a temática da sexualidade, que objetivam a formação dos docentes, disseminadores do assunto, possibilitando-os aprimorar as suas práticas educativas em prol da formação do sujeito em sala de aula (LIMA; JUSTINA, 2019).

Diante dos diálogos ocorridos junto aos docentes do estabelecimento de ensino, todos afirmaram enfrentar barreiras na selação dos conteúdos curriculares. Esses são 
DOI: http://dx.doi.org/10.33238/ReBECEM.2020.v.4.n.1.23922

definidos pela Secretaria Municipal de Educação, que impõe a proposta pedagógica; os docentes apenas a reproduzem em sala de aula. Essa afirmação é discutível, e sabe-se que há parâmetros pedagógicos a serem seguidos, conforme Base Nacional Comum Curricular (BNCC, 2018), porém, o planejamento escolar deve ser feito com a participação coletiva, de toda a comunidade escolar, seguindo os documentos oficiais de educação, tais como os PCNs.

Nesse sentido, salienta-se que os professores contribuíram de forma significativa, demonstrando interesse sobre o assunto, buscando tematizar as discussões e destacando o papel da escola como instituição formadora. As experiências foram satisfatórias, porém é inevitável a não aceitação integral de uma abordagem dessa magnitude por parte de professores da área de ciências exatas, pois, durante a investigação, observou-se resistência dos docentes das disciplinas de Matemática e Física em se envolverem nas ações. Muitos deles priorizavam os conteúdos curriculares de forma tradicional, sem contextualizá-los e problematizá-los, e sem a adoção de padrões que pudessem potencializar a interdisciplinaridade. Na visão deles, essa discussão sobre educação sexual fica sob a responsabilidade dos professores de ciências naturais e/ou humanas.

Nesse contexto, percebeu-se a existência de dúvidas inerentes à saúde sexual e reprodutiva. Além disso, há estereótipos, preconceitos e carência de trabalhos pedagógicos direcionados sobre a temática apresentada. Sabemos da importância da busca por esclarecimentos através de metodologias diferenciadas em sala de aula quanto ao tema em questão. Com base nisso, há a necessidade urgente de integração de propostas educativas no espaço escolar, de forma a contribuir com o conhecimento dos alunos.

A blitz urbana realizada alertou para um posicionamento crítico frente à temática, conscientizando e sensibilizando o público, demostrando a importância da proposta, e sugerindo que discutir sobre o HIV/AIDS é permitir que temas como saúde pública e cuidados com a vida fiquem em evidência para o alcance da sociedade, pois não devem estar restritos apenas à sala de aula.

Dando seguimento às ações, cada turma da escola organizou apresentações para serem expostas à comunidade escolar paralelamente à palestra realizada, cujo tema foi “O contexto histórico, epidemiológico e social do HIV/AIDS". Essa palestra foi proferida por um especialista da área de enfermagem, que esclareceu dúvidas dos discentes sobre educação sexual, aspectos gerais da doença, métodos contraceptivos, riscos e vulnerabilidade frente ao HIV sendo aplicada de forma dinamizada e contextualizada, com linguagem apropriada ao público. 
DOI: http://dx.doi.org/10.33238/ReBECEM.2020.v.4.n.1.23922

A realização de ações, após a palestra, tornou o evento mais dinâmico e atrativo. A galeria “AIDS: o que é, e o que não é!" deu prioridade à explanação das principais ISTs; e na galeria "Combatendo o preconceito", obteve-se resultados aceitáveis diante do objetivo esperado por estarmos diante de assuntos como preconceito e discriminação sexual, promovendo um debate de situações comuns do dia a dia que impendem que muitas pessoas diagnosticadas continuem o tratamento após a descoberta da doença.

A galeria "Tire sua dúvida" proporcionou um diálogo aberto sobre o assunto, esclarecendo questões que já haviam sido expostas na caixa do "Mito ou verdade" e "Tenho dúvidas", que foram disponibilizadas na escola durante o período de preparação das ações, momento no qual surgiram questionamentos. Todos os ambientes foram preparados de acordo com a necessidade do tema, com total apoio da escola e governo municipal através da Secretaria de Saúde.

Houve ausência de alguns pais durante as ações, fato que foi justificado em virtude de motivos particulates. Diante do absentismo desses pais, percebeu-se a necessidade urgente da promoção de ações que busquem resgatar a presença da família na escola, como, por exemplo, a partir de projetos integradores. Diante desse quadro, a equipe desenvolveu a estratégia de entrevistar os pais durante as reuniões escolares conduzidas na pópria escola de forma a obter com segurança as informações aqui veiculadas.

O compartilhamento de ideias foi necessário e urgente. Os alunos demonstraram satisfação quanto às ações desenvolvidas, pois, além de obterem a informação e o esclarecimento de dúvidas, receberam certificados de participação no evento. Segundo Albuquerque et al., (2012), no Brasil as campanhas de prevenção às ISTs são simples repasses de informações verticais, sem estabelecer a reflexão crítica e sem a participação direta do jovem nesse processo, o que o dissocia a informação. Ainda de acordo com Fonseca; Gomes e Teixeira (2010), no país, adolescentes e jovens vêm sendo alvos constantes de pesquisas em virtude dos crescentes índices de HIV/AIDS. Assim, é válida a abordagem da educação sexual com esse público. Sob essa ótica, a escola é um espaço que pode promover o conhecimento e a saúde dos sujeitos.

Diante disso, sugerem-se práticas informativas a partir da criação de tópicos de discussão que direcionem os jovens a buscarem informações para que, dessa forma, desenvolvam comportamentos saudáveis, que os tornem sujeitos corresponsáveis por sua sexualidade e saúde.

\section{Considerações finais}


Diante dos dados apresentados, evidencia-se a necessidade da adoção de medidas e estratégias metodológicas acessíveis ao público escolar. Sabe-se que, durante a adolescência, o indivíduo adquire novos hábitos e comportamentos que se solidificam ao longo dos anos. Sendo assim, as intervenções em educação em saúde para além da sala de aula são importantes, em especial no ambiente escolar, tendo em vista a orientação e sensibilização do público jovem acerca dos cuidados que se estende até à fase adulta. Essas práticas precisam ser vistas como estimuladoras, que favorecem a autorreflexão e a criticidade a partir da práxis pedagógica em sala de aula sobre educação sexual.

As ações executadas contribuíram para o acesso à informação, principalmente aos jovens carentes de conhecimentos sobre prevenção, cuidados e tratamentos de determinadas ISTs, em especial o HIV/AIDS, que acomete principalmente adolescentes e jovens do município de Santa Luzia - MA.

O desenvolvimento desse estudo possibilitou a aquisição de conhecimentos, informações e orientou os jovens e a população quanto aos aspectos essenciais sobre a prevenção do HIV. Dessa forma, procurou-se promover o incentivo ao autocuidado, fazendo com que os sujeitos se tornem corresponsáveis pelos processos e fenômenos inerentes à saúde/doença, utilizando o espaço escolar como veículo de informação. É necessária a discussão da temática na escola de Educação Básica, bem como na sociedade.

Durante a investigação, observou-se o envolvimento e participação ativa do público, demonstrando interesse na temática abordada. Nesse sentido, as metodologias precisam ser diferenciadas e desafiadoras, de modo a aproximar docentes, discentes e sociedade em meio à realidade local, sensibilizando-os sobre os problemas existentes e estimulando a adoção de medidas preventivas que contribuam para práticas seguras de prevenção de ISTs/HIV/AIDS.

O desenvolvimento da proposta sinalizou para a importância de incluir alternativas didáticas na escola, pois se percebeu a carência de trabalhos pedagógicos, principalmente em relação à inexistência de métodos e recursos para a execução das práticas pedagógicas. Apesar da complexidade do tema, por envolver diversos seguimentos sociais, religiosos e culturais, é possível que se estenda à toda sociedade, sobretudo em instituições sociais que lidam diretamente com os jovens e adolescentes carentes de informação e conhecimento sobre educação em saúde.

Diante das atividades realizadas e da conscientização dos alunos, os objetivos propostos pela investigação foram atingidos. Essa proposta evidenciou o quão urgente é 


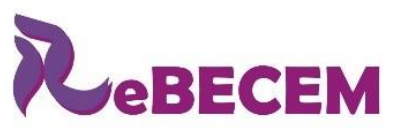

Revista Brasileira de Educação em

Ciências e Educação Matemática

ISSN 2594-9179

DOI: http://dx.doi.org/10.33238/ReBECEM.2020.v.4.n.1.23922

a inserção de políticas educativas nas escolas brasileiras, articulando família e escola em prol da orientação dos sujeitos, pois, de acordo com os resultados apontados, percebeuse que há uma resistência por parte dos pais em relação à discussão da temática no âmbito familiar. Isso contribui para a vulnerabilidade dos jovens ao HIV/AIDS, outras ISTs e gravidez na adolescência.

Portanto, reafirmamos o compromisso e a importância da articulação entre escola e família no estabelecimento de estratégias educativas que possam ser implementadas na escola ou outro ambiente informal de educação. Assim, ficou evidente a aceitação da sociedade, demonstrando que essas práticas são possíveis e podem ser estimuladas, atuando como ferramentas de promoção da cultura dos cuidados em saúde. Por fim, espera-se que essa proposta possa ser utilizada como objeto norteador da práxis pedagógica em sala de aula.

\section{Referências}

ALBUQUERQUE, J. et al. Conhecimento deficiente acerca do HIV/AIDS em estudantes adolescentes: identificação de diagnóstico de enfermagem da NANDA. Revista Eletrônica de Enfermagem, v. 14, n. 1, p. 104-11, 2012.

ANDRADE, M. L. F.; MASSABNI, V. G. O desenvolvimento de atividades práticas na escola: um desafio para os professores de ciências. Ciência \& Educação, v. 17, n. 4, p. 835-854, 2011.

ANGELIM, R. C. M. et al. Conhecimento de estudantes adolescentes acerca do HIV/AIDS. Revista de Enfermagem da UFSM/REUFSM, v. 5, n. 1, 2015.

BRASIL. Conselho Nacional de Saúde. Resolução 196/1996. Dispõe sobre pesquisas envolvendo seres humanos. Brasília: CNS, 1996.

BRASIL. Ministério da Saúde. Conselho Nacional de Saúde. Resolução 510/2016. Dispõe sobre as normas aplicáveis a pesquisas em Ciências Humanas e Sociais cujos procedimentos metodológicos envolvam a utilização de dados diretamente obtidos com os participantes ou de informações identificáveis ou que possam acarretar riscos maiores do que os existentes na vida cotidiana, na forma definida nesta resolução. Brasília: Ministério da Saúde, 2017.

BRASIL. Ministério da Educação. Parâmetros Curriculares Nacionais: Apresentação dos temas transversais e ética. Brasília: MEC, SEF, 1997.

BRASIL. Ministério da Saúde. AIDS perguntas e respostas. Brasília: Ministério da Saúde, 2014. Disponível em: http://portalsaude.saude.gov.br/index.php/links-de-interesse/286aids/9049-o-que-e-aids . Acesso em: 09 nov. 2016.

BRASIL. Ministério da Saúde. PN-DST/AIDS. Serviço de Assistência Especializada (SAE) aos portadores de HIV/Aids. Acesso em: 01 fev. 2020.

BRASIL. Ministério da Educação. Base Nacional Comum Curricular (BNCC). Educação é a Base. Brasília, MEC/CONSED/UNDIME, 2018. Disponível em: 
DOI: http://dx.doi.org/10.33238/ReBECEM.2020.v.4.n.1.23922

http://basenacionalcomum.mec.gov.br/images/BNCC_EI_EF_110518_versaofinal_site.pdf.

Acesso em: 29 set. 2019.

CARPILOVSKY, C. K. et al. Educação Fundamental: ação dos professores frente à temática da educação sexual na escola pública. VIDYA Revista Eletrônica, v. 30, n. 1, p. 43-52, 2010.

COORDENAÇÃO DE DESENVOLVIMENTO DE PROGRAMAS E POLÍTICAS DE SAÚDE - CODEPPS. Manual de atenção à saúde do adolescente. Secretaria da Saúde. São Paulo: SMS, 2006.

COSTA, C. A importância da orientação de jovens escolares quanto à prevenção das IST/AIDS no município de Macau/RN. 2017. Trabalho de Conclusão de Curso (monografia) Universidade Federal do Rio Grande do Norte, Macau, 2017.

COUTINHO, M. F. G. Crescimento e Desenvolvimento na Adolescência. Revista de Pediatria - SOPERJ, suplemento, 2011, p. 28-34.

CUNHA, L. C. Ampliando percepções sobre uso e acesso ao preservativo masculino por adolescentes e jovens: influências do Projeto Saúde e Prevenção nas Escolas, Campo Grande, MS. 2015. Dissertação (Mestrado em Saúde da Família) - Universidade Federal de Mato Grosso do Sul, Campo Grande, 2015.

DOURADO, I. et al. Revisitando o uso do preservativo no Brasil. Revista Brasileira de Epidemiologia, 2015, v. 18, Suplemento 1, p. 63-88.

DUARTE, A. P. Práticas educativas em saúde no ambiente escolar: uma proposta de intervenção. 2015. Trabalho de Conclusão de Curso (Especialização em Estratégia Saúde da Família) - Universidade Federal do Triângulo Mineiro, Uberaba, 2015.

EBERTZ, D. AIDS NO BRASIL: uma análise das publicações da revista veja e do jornal tribuna da imprensa entre os anos de 1982 e 1985. 2017. Trabalho de Conclusão de Curso (monografia). Universidade Federal da Fronteira Sul, Chapecó, 2017.

FONSECA, A.; GOMES, V.; TEIXEIRA, K. Percepção de adolescentes sobre uma ação educativa em orientação sexual realizada por acadêmicos (as) de enfermagem. Escola Ana Nery, v. 14, n. 2, 2010.

FRANCO, N.; SANTOS, W. B.; MAIO, E. R. Docentes da educação básica e a compreensão da sexualidade como conteúdo curricular. Revista Ensino de Ciências e Humanidades - RECH, v. 3, n. 2, p. 27-53, 2019.

GOMES, S. S. S.; OLIVEIRA, M. G.; REZENDE, J. L. P. Educação sexual no ensino médio: aula sobre métodos contraceptivos e ISTs. Pedagogia em Foco, v. 14, n. 12, p. 152-157, 2019.

GRMEK, M. O enigma do aparecimento da AIDS. Estudos Avançados, v. 9, n. 24, p. 229-239, 1995.

LIKERT, R. A technique for the measurement of attitudes. Archives in Psychology, 140, p. 1$55,1932$.

LIMA, W. S.; JUSTINA, L. A. D. A temática sexualidade em atividades extensionistas: um estudo em uma universidade brasileira. Revista Brasileira de Educação em Ciências e Educação Matemática - ReBECEM, Cascavel, v. 3, n. 3, p. 757-777, 2019. 
DOI: http://dx.doi.org/10.33238/ReBECEM.2020.v.4.n.1.23922

MARQUES, M. C. C. Saúde e Poder: a emergência política da AIDS/HIV no Brasil. História, Ciência e Saúde - Manguinhos, v. 9 (suplemento), p. 41-65, 2002.

MINAYO, M. C. S. (org). Pesquisa Social: Teoria, Método e Criatividade. 29. ed. Petrópolis: Vozes, 2010.

NÚCLEO DE ESTUDOS PARA A PREVENÇÃO DA AIDS DA UNIVERSIDADE DE SÃO PAULO - NEPAIDS/USP. Disponível em: http://www.usp.br/nepaids. Acesso em: 29 jul. 2005.

PROGRAMA CONJUNTO DAS NAÇÕES UNIDAS SOBRE HIV/AIDS - UNAIDS.

Estatísticas globais sobre o HIV 2019. Disponível em: https://unaids.org.br/estatisticas/. Acesso em: 29 fev. 2020.

RACHID, M.; SCHECHTER, M. Manual de HIV/AIDS. 10. ed. Thieme Revintern Publicações Ltda. Rio de Janeiro, 2017.

RODRIGUES, J. A. et al. Fatores Contribuintes da Vulnerabilidade Individual dos Jovens ao HIV. Revista Brasileira de Ciências da Saúde, v. 20, n. 2 p. 141-148, 2016.

SANTOS, B. R. P. et al. Jogo educativo como estratégia de educação em saúde para pessoas vivendo com HIV/AIDS. Interdisciplinary Journal of Health Education, v. 4, n. 1, p. 50-54, 2019.

SOUSA, M. Uma análise crítica sobre a sexualidade: a educação doméstica x educação escolar na construção da identidade dos adolescentes. 2015. Trabalho de Conclusão de Curso (monografia) - Universidade Estadual da Paraíba, Campina Grande, 2015.

SOUZA, E. J.; MEYER, D. E. E.; SANTOS, C. Educação sexual no currículo de biologia: entre resistências e enfrentamentos à "ideologia de gênero". Currículo sem Fronteiras, v. 19, n. 2, p. 770-788, 2019.

VILLARINHO, M. V. et al. Políticas públicas de saúde face à epidemia da AIDS e a assistência às pessoas com a doença. Revista Brasileira de Enfermagem, v. 66, n. 2, p. 271-277, 2013.

Recebido em: 21 de janeiro de 2020

Aceito em: 27 de fevereiro de 2020 